\title{
O palácio de cristal: Dostoiévski, cientificismo e a linguagem digital
}

\author{
The crystal palace: dostoevsky, \\ scientificism and the digital language
}

Leonardo Petersen Lamha ${ }^{1}$

Resumo: Este trabalho propõe que a imagem do Palácio de Cristal, articulada por Fiódor Dostoiévski em Memórias do subsolo, pode ser pertinente para representar o mundo digital contemporâneo. Para isso, o artigo investiga o ideal cientificista do século XIX como origem do desenvolvimento da tecnologia digital, com o objetivo de mostrar os primeiros passos de tal linguagem em diálogo com a literatura.

Palavras-chave: teoria da mídia; tecnologia digital; Dostoiévski; Friedrich Kittler; literatura.

Abstract: Starting from the image of the Crystal Palace, used by Dostoevsky to criticize the scientific climate of the 19th century, this article proposes that the same image is useful for discussing our contemporary digital world, understood as the culmination of the same scientific climate on which Dostoevsky lived.

Keywords: Media Theory. Digital Technology. Dostoevsky. Friedrich Kittler. Literature.

\section{O Palácio de Cristal}

Em $A$ arte do romance, Milan Kundera (2009) analisa o desenvolvimento do gênero literário "romance" na Europa comparando-o

1 Mestre em Estudos Literários pela Universidade Federal Fluminense (UFF). 
ao desenvolvimento do espírito científico. Para ele, depois que "a paixão de conhecer se apossou do homem" (KUNDERA, 2009, p. 10), a qual chamaremos neste trabalho de "cientificismo", a ciência foi "reduzindo o mundo a um simples objeto de exploração técnica e matemática" (KUNDERA, 2009, p. 11). Opondo-se à ciência, o romance, enquanto gênero literário, dedicou-se a explorar o ser humano como aquele deixado para trás na escalada científica ocidental.

$\mathrm{O}$ que Kundera deixa de mencionar é que o ser também corria o risco de sofrer a mesma exploração técnica e matemática sofrida pelo mundo. Dentre os muitos exemplos do humano escrutinado pelo cientificismo, está a obra de Fiódor Dostoiévski. Na metade do século XIX, quando o cientificismo já estava em marcha há quase dois séculos, Dostoiévski escreve que, "agora", o homem corre o risco de virar "nota de piano ou pedal de órgão" (DOSTOIÉVSKI, 2009, p. 37). Em Memórias do subsolo, ele representa essa ameaça com a imagem grandiosa do Palácio de Cristal.

Gigantesca construção de vidro e armação de ferro inaugurada em Londres em 1851, o Palácio de Cristal abrigou uma faraônica exposição na qual foram exibidas conquistas científicas e artísticas de todos os períodos da humanidade. Dentro do Palácio, anota o visitante Dostoiévski,

sente-se uma força terrível, que uniu num só rebanho todos estes homens inumeráveis, vindos do mundo inteiro. Tem-se consciência de um pensamento titânico. Não será o fim? Não será este, de fato, o "rebanho único" Não será preciso considerálo como a verdade absoluta e calar para sempre? (DOSTOIÉVSKI, 2000, p. 114).

Pensamento titânico, rebanho único. Nesse primeiro momento, Dostoiévski somente registra seu espanto. Entretanto, dois anos depois da visita ao Palácio de Cristal, Dostoiévski retorna ao tema com um ataque 
direto à construção. Na primeira parte de Memórias do subsolo, o narrador imagina um mundo onde o homem foi completamente mapeado, não tendo mais vontade nem caprichos, um mundo onde tudo procede de acordo com leis pré-estabelecidas e,

consequentemente, basta descobrir essas leis e o homem não responderá mais pelas suas ações. Todos os atos humanos serão calculados, está claro, de acordo com essas leis, matematicamente, como uma espécie de tábua de logaritmos. Nesse mundo, tudo será extremamente sensato. Erguer-se-á, então, um palácio de cristal. (DOSTOIÉVSKI, 2009, p. 38-39).

Por ser de cristal, as paredes do palácio são transparentes, de modo que não se poderá nem "dar a língua", como diz o narrador. Contudo, continua ele, mesmo isso não seria um problema, já que as leis da ciência terão se encarregado de mapear, e, por conseguinte, controlar o homem, a tal ponto que ele não sentirá mais vontade de transgredir. É nesse mundo, ou contra esse mundo, que se inscreve a crítica a tudo que é racional, científico e lógico - o cientificismo - perpetrada pelo Homem do Subsolo. Através da autodepreciação, da autoflagelação e do ódio autodirigido, ele tenta provar que age por impulsos impossíveis de serem mapeados.

Quem narra é, sim, "um homem doente, um homem mau" (DOSTOIÉVSKI, 2009, p. 15), como se apresenta o narrador. Entretanto, também um homem culto. Segundo René Girard (1965, p. 56), "um homem culto não consegue ser vaidoso sem elencar altos padrões a si mesmo, e sem odiar a si mesmo em certos momentos" ${ }^{2}$. Tal ódio, na argumentação psicanalítica de Girard, não poderia ter sido gerado na subjetividade do sujeito; ao contrário, só pode ter vindo de fora, do mundo.

2 Todas as traduções para o português das obras estrangeiras referenciadas neste artigo são de autoria nossa. 
Esse "fora" parece referir-se justamente ao contexto cientificista do século XIX destacado por Dostoiévski, um contexto que impõe às pessias, inclusive ao Homem do Subsolo, uma falsa promessa:

Aos olhos de Dostoiévski, essa falsa promessa era uma premissa de autonomia metafísica: Deus está morto, o homem deve tomar seu lugar. $\mathrm{O}$ orgulho torna-se irresistível nos tempos modernos, amplificados e organizados de modo nunca antes visto [...]. Quanto mais profundamente a promessa é talhada em nossos corações, mais violento será o contraste entre ela e decepção brutal infligida pela experiência (GIRARD, 1965, p. 56).

Em outras palavras, por acreditar que a subjetividade está ameaçada pelo Palácio de Cristal, o Homem do Subsolo busca sempre experiências que neguem a verdade doutrinária do cientificismo, provando, por meio da autoimolação e do sofrimento, que o cientificismo está errado, que o ser humano é, ou pode ser, metafisicamente outro (que não máquina). Assim ele procura viver nas paredes transparentes do Palácio de Cristal.

Vivendo no século XIX, o Homem do Subsolo pode se dar ao luxo de dizer que, talvez, "tal palácio [fosse] uma invencionice sua"; que, talvez, o Homem do Subsolo o tenha "inventado unicamente em virtude da própria estupidez e de alguns hábitos antigos, irracionais, da nossa geração" (DOSTOIÉVSKI, 2009, p. 49). De fato, no final do XIX, era possível dar-se ao luxo de chamar o Palácio de Cristal de invencionice. Teríamos hoje o mesmo privilégio? A imagem da humanidade espremida entre janelas de vidro transparentes, num êxtase de cristais, luz e cores, matematicamente mapeada e visível para todos - isso não lembra uma outra imagem, mais cotidiana e normalizada? Não haveria, no Palácio de Cristal de Dostoiévski, um clima de dócil submissão e vigilância semelhante ao surgido no advento e na democratização da tecnologia digital? 


\section{Linguagem digital}

Um detour pelo pensamento cientificista do século XIX, no contexto da criação do protótipo do computador pode nos ajudar a demonstrar nosso ponto.

A palavra "digital", é claro, vem de "dígito", que, por sua vez, tem relação com os "pontos discretos" da res cogitans cartesiana, a razão discreta, localizável e verificável que se põe em oposição ao contínuo sem limites da natureza (MÜLLER, 2013, p. 6), Aprofundando-nos nessa relação, discutiremos como o computador surge de um cartesianismo filosófico-linguístico com uma linguagem que vira "carne".

Para representar o pensamento puro, era preciso antes criar uma linguagem científica livre de subjetividades, mecânica e automatizada, uma linguagem-manual-de-instruções, que depois alimentará nossos computadores e projetará o nosso palácio de cristal. Buscarei essa linguagem por meio do seguinte trajeto: 1) uma discussão sobre as condições históricofilosóficas em que estava envolvido Charles Babbage, responsável pela criação da Analytical Engine, a primeira máquina automática de calcular, e 2) uma investigação sobre Isaac Newton, que se esforçou para transformar a linguagem humana numa janela para o pensamento puro. Ambas as discussões foram travadas por críticos literários e escritores: Hugh Kenner e J.M. Coetzee.

Contra o pano de fundo do pensamento científico-positivista no século XIX, Kenner, esquecido e brilhante crítico do modernismo, analisa em sua obra The Counterfeiters ["Os falsificadores", em tradução livre] os escritos, o pensamento e as invenções de Babbage, responsável pela criação da Analytical Engine, o protótipo do computador projetado durante Revolução Industrial, máquina cujo objetivo era traduzir procedimentos lógico-abstratos em procedimentos mecânicos.

Tal projeto era "o mais amplo e querido da Royal Society" 
(KENNER, 2005, p. 39). Para chegar a ele, precisou-se desenvolver uma linguagem que consistia numa alquimia entre a lógica aristotélica, a filosofia platônica, e o mecanicismo racional cartesiano, seguindo a premissa de que o ideal precede o visível. Primeiro, idealiza-se um mundo mecânico e racional bem determinado por leis. Em seguida, a linguagem procura tornar visível esse ideal,

uma linguagem que, na medida em que você dominalhe uso e poda seus pensamentos de acordo com normas de elegância determinadas, o impele a se comportar como se você fosse um animal racional, fornecendo [assim] à mente conexões prescritas entre uma coisa e outra coisa (KENNER, 2005, p. 39, grifos nossos).

J. M. Coetzee tratou de explicar, com base em Isaac Newton, o arquétipo dessa "visão mecanizada do pensamento" (COETZEE, 2011, p. 184). Segundo ele, Newton foi quem mais tentou purificar as "conexões entre uma coisa e outra coisa", ou seja, entre sujeito e objeto, entre o que diz a linguagem e do que ela diz. Analisando as anotações de Newton, Coetzee nota que o ideal da Royal Society, de que Charles Babbage fazia parte, era livrar a linguagem de toda ambiguidade, visando aproximá-la da objetividade ideal do pensamento matemático puro.

Como exemplo, Coetzee utiliza a teoria da gravidade de Newton, à época criticada como medievalista e ocultista por conta do emprego de palavras ambíguas como "força" e "atração". Contra essas críticas, Newton argumentava que, embora não soubesse explicar as causas das atrações entre os corpos, para a ciência "basta que a gravidade exista e aja de acordo com as leis [da atração] que explicamos" (COETZEE, 2011, p. 187). Definido matematicamente, o termo "força" perde sua ambiguidade, seu referencial no mundo, e adquire significado referencial à Lei da Gravidade de Newton. Assim a força de atração da gravidade pode ser verificada empiricamente, 
quaisquer que fossem suas causas, pois sua referencialidade ambígua na linguagem cotidiana dá lugar à referencialidade abstrata e definida da, e na, teoria. De tal forma, a linguagem cristalina do pensamento puro promove um "mapeamento não ambíguo da realidade, de razão 1:1, atingindo a plenitude matemática que era o ideal da Royal Society na época de Newton" (COETZEE, 2011, p. 189).

Como que retroativamente, esse raciocínio projeta uma realidade igualmente ideal e objetiva a ser experimentada sem erros pelo intelecto do homem, uma vez que este também havia sido definido anteriormente como o ser racional por excelência. Logo,

se o pensamento corre a partir de um a priori, todas as suas fases podem ser imitadas, até mecanizadas. $\mathrm{O}$ computador simula o pensamento já que o pensamento foi definido de um jeito computacional; e o autômato simula o humano, uma vez que o humano foi definido como ser automatizado (KENNER, 2005, p. 40).

Por "autômato", entenda-se "computador". Kenner utiliza o verbo "simular" para referir-se ao procedimento lógico-matemático do computador, então concebido apenas para imitar o pensamento. Ora, “imitação" e "simulação" são os termos com os quais se costumava referir aos procedimentos do então emergente computador, entendido como simulador do cérebro humano. Entretanto, no século XIX, ninguém “os denominaria de simuladores, mas sim de brinquedos ou ferramentas, já que eram utilizados por humanos que eram, metafisicamente, outra coisa" (KENNER, 2005, p. 40). Em outras palavras, no século XIX, um computador só podia ser concebido como brinquedo pois o homem era o único que pensava “à sério". Babbage queria provar o contrário.

Podemos agora voltar a Dostoiévski. Se o Homem do Subsolo se recusava a tornar-se pedal de órgão, era porque ele se imaginava 
metafisicamente como outra coisa, de modo que toda máquina só podia ser concebida como brinquedo. O referencial, o ponto de vista, estava sempre no ser humano. Já Kenner, ao utilizar o termo "simulação" na década de 70 , mostrava que, a partir de Babbage, os tais brinquedos atingem status metafísico, e, portanto, o homem passa a ser enxergado pelo ponto de vista do computador e da ciência que o compunha: "Se um homem não faz nada da vida além de tear fios, então como uma máquina de tear [não poderia ser vista] como um homem purificado?" (KENNER, 2005, p. 40).

\section{A concretização do ideal}

As muitas amostras da prosa de Charles Babbage, citado por Kenner como uma espécie de percursor de Samuel Beckett, dão mostras do cientificismo nascente no século XIX. Tratam-se de verdadeiros manuais de instruções para, por exemplo, reproduzir mecanicamente os detalhes de um ramo de brócolis (KENNER, 2005, p. 105) ou divisar um método para que "vinte mil agulhas jogadas aleatoriamente numa caixa possam ser reposicionadas e viradas para frente para serem vendidas" de modo automático (KENNER, 2005, p. 103).

$\mathrm{O}$ sonho de Charles Babbage era que processos intelectuais matemáticos pudessem se tornar mecanicamente reproduzidos. Portanto, projetou uma máquina capaz de retirar os números da esfera do ideal e trazê-los para o mundo concreto. A metáfora efetivamente utilizada para essa máquina era apropriada ao século XIX: a fábrica. A Analytical Engine, o protótipo dos nossos computadores, equivaleria a uma fábrica cartesiana de números. Uma máquina de várias toneladas, alimentada por cartões perfurados por onde receberia instruções ("programas"), capaz de realizar operações algébricas que reduziriam o mundo à clareza da matemática. A Analytical Engine representaria a realização do sonho do ideal cientificista do século XIX, "um mundo perfurado, dobrado, grampeado e mutilado" 
(KENNER, 2005, p. 108).

Kenner resume a função do computador - incluindo aí sua relação com o pensamento e o conhecimento - com um arco que começa na Grécia, passa por Descartes, e chega até o século XXI:

Para Sócrates, virtude é conhecimento... Essa é também a virtude do computador, que não possui nenhuma outra senão ser um método. É o animal racional perfeito. Nós o construímos, depois o programamos; tudo que o ensinamos precisa estar já potencialmente conhecido, uma vez que suas proposições estão essencialmente imbricadas em sua estrutura física [...]. O computador é o sonho de Sócrates, para quem o método e a razão delineavam os contornos do mundo ideal. (KENNER, 2005, p. 140-141).

A mesma convergência entre procedimentos mecânicos e idealismo intelectual pode ser descoberta na primeira programadora da história, ninguém menos que uma das filhas bastardas de Lord Byron (como se a prole do romantismo se valesse da razão para se rebelar contra o pai, em oposição ao que se esperava da mulher): Ada Lovelace, assistente de Charles Babbage. Em suas notas sobre o projeto da Analytical Engine, e com pragmatismo invejável, Ada escreve:

Aqueles que consideram as verdades matemáticas como o instrumento através do qual a fraca mente humana pode melhor ler as obras do Criador verão com especial interesse tudo que facilitar a tradução dos Seus princípios em formas práticas explícitas (LOVELACE, 1842).

Com isso, Ada Lovelace reafirma o computador como instrumento de concretização do cientificismo que buscava acesso direto à natureza. 
Porém, em meados do século XIX, nem Ada Lovelace, nem Charles Babbage, nem mesmo Hugh Kenner podiam antever que suas investigações resultariam num palácio mais cristalino do que a pesada maquinaria da Inglaterra Industrial. Mais cristalino, porém ainda assim fundamentado sobre a mesma base: o dígito.

\section{O digital}

“À frente a luz e atrás de mim a treva. / Aos pés, o oceano, e o empíreo sobre mim. / Um sonho, enquanto afunda em fluídos de cristal (GOETHE, 2004, p. 114). Para que esse trecho do Fausto fosse uma perfeita descrição da geolocalização realizada por nossos atuais GPS, só faltaram coordenadas cartográficas. De tal maneira, ele ilustra bem o que é um dígito. Fausto contempla o pôr-do-sol a partir de um ponto específico no tempo e no espaço: acima do oceano, abaixo do céu, no momento em que o dia vira noite, marcando, portanto, a divisão do céu crepuscular em dois, metade luz e metade trevas. Fausto está perfeitamente diferenciado da natureza contínua que o engloba, representando a função do dígito: um ponto discreto destacado da continuidade indivisível da natureza. Destacando e fixando um ponto, o Fausto-dígito também ilustra a digitalização do mundo.

A grande revolução na história humana não é a prensa tipográfica nem as navegações, mas o contínuo processo de digitalização do mundo desde a Renascença. Filósofos e cientistas como Descartes e Newton estão lidando com o confronto entre uma razão matemática, discreta (res cogitans) e uma natureza contínua (res extensa). A Modernidade não é nada menos que a vitória - se excluirmos a Razão e a Arte - da res cogitans sobre a res extensa. Desde então, o homem "controla" a natureza e a vida com números. $\mathrm{O}$ que significa que: o mundo 
foi digitalizado. Bill Gates e Steve Jobs estão apenas acelerando o trabalho de Descartes e Newton criado no século dezessete. (MÜLLER, 2013, p. 6)

Mundo digitalizado, vitória da razão discreta. Assim é como Vilém Flusser entende as vantagens da transparência objetiva do digital em relação à velha ambiguidade (contínua) da linguagem textual:

Há 450 anos surgiu a forte suspeita que a natureza é indescritível, mas contável; que, portanto, textos não são um bom código quando se trata de formular um saber [...] O código numérico é claro e distinto, enquanto o código linguístico é ambíguo (FLUSSER, 2014, p. 30).

Flusser refere-se à ciência de modo geral. No entanto, os números concretizam, de modo específico e determinante, na linguagem do hardware da tecnologia digital. De acordo com o crítico literário e teórico da mídia Friedrich Kittler:

A tecnologia digital funciona como um alfabeto, mas sobre uma base numérica. Ela substitui as funções contínuas, nas quais as mídias analógicas [não digitais] transformam informações também contínuas, por pontos discretos no tempo (KITTLER, 1996).

Transformada a natureza contínua em dígitos, ela pode ser calculada, armazenada, processada, reproduzida, mecanizada.

Contudo, não se vê números quando se usa o computador. Saltando bruscamente sobre a longa e complicada história técnica de como esses números passaram a nos mostrar imagens, tomemos esse processo como dado. 
Em 1990, o Palácio de Cristal dos primeiros computadores pessoais possuía baixa resolução e poucas cores. Basta olhar as imagens e interfaces da época a partir da perspectiva presente para desconfiarmos, como Dostoiévski do cientificismo, de sua capacidade representativa. Essa é a suspeita de Flusser em Aparição digital (1996).

Escrito em 1991, ano da morte de Flusser, esse ensaio trata das imagens que emergiam das telas de computador da década de 80 e 90: "linhas, superfícies, e corpos, feitos de pontos e cálculos." (FLUSSER, 1996, p. 242). Se o palácio de cristal ameaçava transformar o ser humano em pedais de órgão, com os computadores ele passa a ser entendido como "curvaturas e convexidades num ponto de entrecruzamento de relações, especialmente humanas. Somos 'computação digital' de pontospotencialidades" (FLUSSER, 1996, p. 244).

Já que essa perspectiva sobre o humano assume o olhar estrangeiro do computador, Flusser chama seu insight de "nova antropologia": "não basta reconhecer o self como um nódulo de virtualidades entrecruzadas, um iceberg flutuando num mar de inconsciência [...]: é preciso também agir de acordo" (FLUSSER, 1996, p. 244). Por quê? Porque o computador, ele próprio, age; ele próprio é pura ação - tão elétrica quanto era mecânica a Analytical Engine de Babbage. As operações matemáticas que ele realiza, portanto, não podem ser entendidas como mera descrição ou reprodução matemática do mundo ideal apriorístico, como nos séculos XVIII e XIX, "mas sim [como] uma transformação desse entendimento em agência" (FLUSSER, 1996, p. 245).

Tal transformação crucial significa uma mudança no modo de se enxergar o ser humano. Dostoiévski, refletido pelo palácio de cristal, se sentia ameaçado de ser visto como transparente, mapeado, pedal de órgão. Só que seu Palácio de Cristal não agia por conta própria, não computava: ele era como uma janela numa torre de vigilância. Já o computador, pela primeira vez na história, pode computar autonomamente o mundo. Esse 
poder de agência do computador transforma o ser humano que computa, também ele, em computador

O que fazem os que se sentam em frente aos computadores, que apertam teclas, que produzem linhas, superfícies e corpos? O que eles realmente estão fazendo? Estão realizando possibilidades. Computadores são aparatos para a realização de possibilidades inter e entre-humanas, graças ao pensamento calculatório exato. Essa formulação pode ser entendida como uma definição possível de 'computador' (FLUSSER, 1996, p. 244).

Embora aja sobre a mesma base computacional, o nosso Palácio de Cristal atual é diferente do descrito por Flusser. Não enxergamos linhas nem superfícies geométricas, mas um mundo sensorial e realista. Nossas telas de cristal líquido reagem com fluidez aos nossos dedos, enquanto estes, por sua vez, sentem a sensualidade e o poder de controlar um fluxo de informação infinito, apresentado sob a forma de um design belo e user-friendly que oculta a real natureza de calculadora do computador. Enxergamos a mensagem, não a mídia. Se o meio ainda é a mensagem (MCLUHAN, 1994), a história da computação, coroação do casamento entre lógica e natureza e do cientificismo que ameaçava Dostoiévski, parece empenhada em tornar a máxima de McLuhan cada vez mais difícil de ser verificada. Resta, hoje, saber como enxergar o ser humano que computa e não sabe que computa. "Usuário" parece-nos um bom termo para atualizar o pedal de órgão de Dostoievski.

$$
* * *
$$

Uma das premissas ocultas deste trabalho é que a literatura e a 
crítica literária podem dialogar com o nosso estado de coisas tecnológico. As aflições de Dostoiévski parecem apropriadas para lidar com a convergência entre linguagem, tecnologia e ciência, as quais, por sua vez, convergem no nosso presente sob a forma da tecnologia digital. Se considerarmos que nosso mundo se midiatizou a tal ponto que a própria noção de mídia ameaça desparecer de vista, perseguir essa convergência soa apropriado como instrumento de investigação do presente. Tentamos mostrar que a literatura pode participar dessa pesquisa.

Para concluir, termino com uma citação de Friedrich Kittler. Se a tecnologia representa a concretização do pensamento científico, como vimos no caso da linguagem digital, e se as interfaces técnicas escondem o pensamento que as originou, então é possível dizer que as mídias enganam nossos sentidos. "E se as mídias enganam nossos sentidos, é completamente plausível que as concebamos como inimigas [...] Pois o inimigo é sempre a incorporação das nossas próprias questões" (KITTLER, 2010, p. 34).

\section{Referências}

COETZEE, J. M. Doubling the point: essays and interviews. Cambridge: Harvard University Press, 2011.

DOSTOIÉVSKI, Fiódor. Memórias do subsolo. São Paulo: Editora 34, 2009.

. O crocodilo e Notas de inverno sobre impressões de verão. São Paulo: Editora 34, 2000.

FLUSSER, Vilém. Comunicologia: reflexões sobre o futuro: as conferências de Bochum. São Paulo: Martins Fontes, 2014.

. "Digital Apparition". In: DRUCKERY, Timothy (ed.) Electronic

Culture: Technology and Visual Representation. London: Aperture, 1996, pp. 242-245.

GIRARD, René. Deceit, Desire, and the Novel: self and other in literary 
structure. Baltimore: The John Hopkins Press, 1965.

GOETHE, Johann Wolfgang von. Fausto: uma tragédia - Primeira parte. São Paulo: Editora 34, 2004.

KENNER, Hugh. The Counterfeiters. London: Dalkey Archive Press, 2005.

KITTLER, Friedrich. History of Communication Media. CTheory: Global Algorithms. Disponível em: https://journals.uvic.ca/index.php/ctheory/ article/view/14325/5101. Acesso em: 08 jun. 2019.

. Optical Media: Berlin Lectures 1999. Cambridge: Polity Press, 2010.

KUNDERA, Milan. A arte do romance. São Paulo: Companhia das Letras, 2009.

LOVELACE, Ada. Sketch of the Analytical Engine, Invented by Charles Babbage. With notes upon the Memoir by the Translator Ada Augusta, Countess of Lovelace. Bibliothèque Universelle de Genève, 1842. Disponível em: http://www.fourmilab.ch/babbage/sketch.html. Acesso em: 08 jun. 2019

MCLUHAN, Marshall. Understanding Media: The Extensions of Man. Cambridge: MIT Press, 1994.

MÜLLER, Adalberto. The Dark Side of the Digital Shines on your Crazy Keyboards. Comunicação apresentada na conferência The Dark Side of The Digital, Center for 21st Century Studies Conference, Milwaukee, 2013. Disponível em: http://www.academia.edu/3430148/THE_DARK_ SIDE OF THE DIGITAL ON KITTLER AND FLUSSER. Acesso em: 08 jun. 2019.

Recebido em: 28/10/2019

Aprovado em: 09/06/2020 